\section{A comparison of models for quantifying growth and standing carbon in UK Scots pine forests}

\author{
Jack Lonsdale $^{(1)}$, Georgios Xenakis ${ }^{(2)}$, Maurizio Mencuccini ${ }^{(3)}$, Mike \\ Perks (2)
}

Scots pine is the most abundant native conifer in the UK. A stand level dynamic growth (SLeDG) model is parametrised for British Scots pine stands for the first time. This model predicts stands annually based on their current state, and allows for changes in forest management. Stand growth and carbon storage predictions using this model were compared with those of the yield look-up package ForestYield, and a process-based model (3PGN). Predictions were compared graphically over an 100 year rotation, and strengths and weaknesses of each were considered. The SLeDG parametrisation provided forecasts of Scots pine growth with percentage mean absolute difference $<12 \%$ for all state variables. The model comparison showed that similar outputs were predicted by all three models, with the greatest variation in the yield table based prediction of volume and biomass. Future advances in data availability and computing power should allow for greater use of process-based models, but in the interim more flexible dynamic based growth models may be more useful than static yield tables for providing predictions which extend to non-standard management prescriptions and estimates of early growth and yield.

Keywords: Growth, Yield, Carbon, Modelling, Dynamical-systems, 3PG, ForestYield

\section{Introduction}

The combination of both spatial scale and rotation length of forest stands mean that models of forest growth are essential for sustainable management (Blanco et al. 2008). Historically this has been achieved using yield models which use empirical relations between state variables such as top height, basal area, and number of stems to forecast stand development and timber volume production (Vanclay 1994). For example, in the UK there is widespread use of the yield tables of Edwards \& Christie (1981) provided through a lookup package ForestYield. Increased emphasis on providing a multifunction forest resource (Nijnik \& Mather 2007) has meant that such models have had to be applied to activities such as carbon storage reporting (Dyson et al. 2009). However, forest managers focusing on multi-function

management are in turn more likely to deviate from management regimes aimed only at maximising timber production. Another shortcoming of such yield tables is that they fail to be linked causally to the drivers of productivity such as climate and nutrient availability, and are unable to account for changes in these drivers as might be expected in a changing climate (Monserud 2003). A shift to more flexible forest models is appropriate to accommodate for changes in environment or management objectives.

Hybrid models combine both empirical and process based modelling approaches: using simple mathematical relationships between stand variables, and representations of the underlying ecophysiological processes in stand development respectively. Through the combination, shortcomings of the empirical and process-based approaches may be ame-

(1) School of Geosciences, University of Edinburgh, Edinburgh EH9 3JN (UK); (2) Forest Research, NRS, Roslin, Midlothian EH25 9SY (UK); (3) ICREA at CREAF, Cerdanyola del Valles, Barcelona (Spain)

\section{@ Jack Lonsdale (jacklonsdale@ed.ac.uk)}

Received: Jul 21, 2014 - Accepted: Jan 09, 2015

Citation: Lonsdale J, Xenakis G, Mencuccini M, Perks M, 2015. A comparison of models for quantifying growth and standing carbon in UK Scots pine forests. iForest 8: 596-605 [online 2015-02-02] URL: http://www.sisef.it/iforest/contents/?id=ifor1403-008

Communicated by: Emanuele Lingua liorated (Landsberg 2003, Monserud 2003), providing both traditional outputs for forest managers as well as estimates of carbon sequestration, whilst reducing the uncertainty in model outputs that occurs in complex process modelling (Valentine \& Mäkelä 2005). Additionally, prediction precision may be improved by using a hybrid approach which can deal with changes in growing environment not represented in empirical models (Pinjuv et al. 2006).

There are a number of hybrid models which have been applied for varied species and locations globally (Valentine \& Mäkelä 2005, Weiskittel et al. 2009a, Mason et al. 2011). Perhaps the most widely applied hybrid model is Physiological Principles Predicting Growth (3PG) developed by Landsberg \& Waring (1997). It uses physiological principles as the basis for a relatively simple process-based model that can provide forest managers with stand variables as well as estimates of carbon fixation. The model works in three stages: derivation of primary production, partitioning the production to above and below ground portions, and derivation of output variables (Landsberg et al. 2003). It has been parametrised successfully for a number of species, including: eucalyptus (Eucalyptus spp.) in Australia (Sands \& Landsberg 2001), Brazil (Almeida et al. 2010), Spain (Pérez-Cruzado \& Muñoz Sáez 2011) and Portugal (Minunno et al. 2012); ponderosa pine (Pinus ponderosa Douglas ex C.Lawson) and Douglas fir (Pseudotsuga menziesii (Mirb.) Franco) in the Pacific Northwest (Swenson et al. 2005), and in the UK for Scots pine (Pinus sylvestris L. Xenakis 2007) and Sitka spruce (Picea sitchensis (Bong.) Carr. - Minunno et al. 2010). However, while 3PG has the potential to be used over large areas where it has not been calibrated (Almeida et al. 2010), it still requires a large number of parameters to be measured or estimated (both climatic and in the stand). This may increase both model uncertainty and the cost of parametrisation, especially in cases with limited data availability.

Another class of models which can have elements of flexibility in the sense described above are dynamic yield models as suggested by Pretzsch (2010). Dynamic yield models allow forecasting of a stand based on its current state, as measured by a number of state variables (such as top height, basal area, and number of stems per hectare). Changes in a state variable are a function of only the current state of the stand. Thus variation in forest management strategies can easily be modelled by adjusting state variables accordingly. For example, a thinning may be modelled by reducing the number of stems and the basal area in the state vector, creating an adjusted state vector. The trajec- 
tory of this adjusted state vector is then forecast. This would not be possible with a static yield model, where only predetermined points for thinnings can be simulated.

A number of stand level dynamic growth (SLeDG) models have been developed for a variety of species based on the initial work of García (1979): for eucalypts (Eucalyptus globulus Labill.) in Spain (García \& Ruiz 2003), Sitka spruce in Ireland (Broad \& Lynch 2006), interior spruce - a mix of white spruce (Picea glauca [Moench] Voss), and Engelmann spruce (Picea engelmannii Parry) and their hybrids - in British Columbia (García 2011), loblolly pine (Pinus taeda L.) in the Piedmont region of the USA (García et al. 2011), and trembling aspen (Populus tremuloides Michx.) in Western Canada (García 2013). This approach has an advantage in that SLeDG models may be parametrised providing acceptable extrapolations with relatively small Permanent Sample Plot (PSP) datasets (García 2011). As the UK has a robust but not particularly extensive network of PSPs (Scots pine $n=196$; Sitka spruce $n=488$ ), such models are advantageous. Changes in stand-level variables are predicted with biologically consistent differential equations. Recent SLeDG style models have moved towards more of a hybrid style, including variables which account for reduction of productivity following thinning or topping in turn reducing the stand's photosynthetic (and nutrient capture) apparatus (García et al. 2011). In the most recent implementation of the model framework it is suggested that the model may allow for estimating the root, leaf, and branch biomass of stands (García et al. 2011), thus providing both timber growth estimates, and a standing biomass estimate for forests. It is also sug- gested that the model productivity may be modulated by climate and nutrient parameters, allowing for predictions in a changing climate (García et al. 2011). However, neither the standing carbon nor climate change predictions have been tested yet. Additionally, unlike 3PG there has been no work on integrating the model with routines of soil carbon dynamics (Xenakis et al. 2008), which are an important component of the forest carbon cycle (Jandl et al. 2007).

While there can be no "perfect model", certain models will lend themselves better than others to certain tasks. Here we do not aim to determine a perfect model, but instead compare model utility for different tasks. This paper has two objectives. Firstly, we introduce the use of the SLeDG approach in UK forests. The model is described and parametrized for Scots pine. Scots pine is the most abundant native conifer in the UK, and the second most abundant overall species - occupying over $17 \%$ of the UK forest area (Forestry Commission 2011). With current forest strategy aiming to afforest with native species, Scots pine's importance in UK forestry looks set to increase (Woodland Expansion Advisory Group 2012). Timber outputs, as well as standing carbon outputs are estimated and reported for the first time with a SLeDG model.

Secondly, forecasts of forest growth and standing carbon estimates of the SLeDG model are compared with those of the ForestYield package and the 3PGN model. Although versions of $3 \mathrm{PG}$ have previously been compared with other growth models (Pinjuv et al. 2006, Weiskittel et al. 2009a), the ForestYield model has not previously been compared to alternative modelling methods for forest carbon accounting. This therefore allows a comparison of the outputs of these forest growth models, as well as identifying the potential for improving the current methodology for stand level forest growth and carbon reporting estimations.

\section{Methods}

\section{Data}

The data for the parametrisation of the models were provided by the Forest Research Forest Mensuration, Modelling and Forecasting Group, consisting of 51 PSPs across Scotland. The measurement statistics taken from these PSPs are summarised by age group in Tab. 1 .

These plots were planted with Scots pine between 1878 and 1965. Measurements were taken from stands ranging in age between 14 and 125 years, with at least two mensurational surveys per plot. Plots varied in their management with a variety of thinnings undertaken.

Thirteen plots were unthinned controls. Four soil types were selected on Ecological Site Classification (Pyatt et al. 2001): podzol, brown earth, sand and podzol/brown earth mixture; and 45 soil sample plots were collected as part of an earlier study (Xenakis 2007). The elevation of both PSP and soil plots ranged from 3 to $364 \mathrm{~m}$ a.s.l., and were located between latitude $56^{\circ} 63.1^{\prime}$ and $57^{\circ}$ $69.3^{\prime} \mathrm{N}$ and longitude $5^{\circ} 19.7^{\prime}$ and $3^{\circ} 07.0^{\prime}$ W.

\section{Model definitions}

\section{SLeDG}

This version of the SLeDG model is an adaptation of the model by García et al. (2011), which is an evolution of the model

Tab. 1 - Summary of measurements from Permanent Sample Plots by age group.

\begin{tabular}{|c|c|c|c|c|c|c|c|c|}
\hline Plots & Parameter & Mean & SD & Min & $1^{\text {st }}$ Quartile & Median & $3^{\text {rd }}$ Quartile & Max \\
\hline Young plots & Age & 31.2 & 6.42 & 14.0 & 28.0 & 32.0 & 37.0 & 39.0 \\
\hline \multirow[t]{6}{*}{ (Age $<40$ years, $n=88$ ) } & Top height (m) & 12.6 & 2.11 & 6.80 & 11.1 & 12.6 & 14.1 & 16.6 \\
\hline & Stems ha ${ }^{-1}$ & 2059 & 1150 & 608 & 1212 & 1755 & 2606 & 6125 \\
\hline & Basal area $\left(\mathrm{m}^{2}\right)$ & 31.4 & 8.26 & 16.9 & 26.5 & 29.9 & 34.9 & 53.5 \\
\hline & Volume $\left(\mathrm{m}^{3}\right)$ & 168 & 65.2 & 45.9 & 118 & 175 & 209 & 290 \\
\hline & Yield Class $\left(\mathrm{m}^{2} \mathrm{ha}^{-1} \mathrm{yr}^{-1}\right)$ & 10.2 & 1.68 & 7.0 & 9.0 & 10.0 & 11.0 & 14.0 \\
\hline & Initial Spacing (m) & 1.50 & 0.48 & 0.90 & 1.20 & 1.40 & 1.80 & 2.40 \\
\hline \multirow{7}{*}{$\begin{array}{l}\text { Middle-aged plots } \\
(40 \leq \text { Age }<70 \text { years, } \\
n=140)\end{array}$} & Age & 53.1 & 7.75 & 40.0 & 46.0 & 51.0 & 60.0 & 69.0 \\
\hline & Top height (m) & 18.1 & 2.48 & 12.0 & 16.5 & 18.3 & 19.8 & 23.9 \\
\hline & Stems ha ${ }^{-1}$ & 1196 & 792 & 792 & 561 & 934 & 1703 & 3948 \\
\hline & Basal area $\left(\mathrm{m}^{2}\right)$ & 40.1 & 9.64 & 23.7 & 32.1 & 37.75 & 49.0 & 63.9 \\
\hline & Volume $\left(\mathrm{m}^{3}\right)$ & 304 & 78.5 & 165 & 245 & 295 & 354 & 553 \\
\hline & Yield Class $\left(\mathrm{m}^{2} \mathrm{ha}^{-1} \mathrm{yr}^{-1}\right)$ & 9.67 & 1.66 & 4.0 & 9.0 & 10.0 & 10.0 & 14.0 \\
\hline & Initial Spacing $(\mathrm{m})$ & 1.45 & 0.47 & 0.90 & 1.20 & 1.40 & 1.80 & 2.40 \\
\hline Old plots & Age & 87.37 & 11.8 & 71.0 & 79.0 & 87.0 & 94.8 & 115 \\
\hline \multirow[t]{6}{*}{ (Age $\geq 70$ years, $n=38$ ) } & Top height (m) & 21.26 & 4.12 & 13.0 & 19.3 & 21.7 & 24.2 & 27.9 \\
\hline & Stems ha-1 & 631 & 337 & 259 & 368 & 496 & 787 & 1473 \\
\hline & Basal area $\left(\mathrm{m}^{2}\right)$ & 43.9 & 13.2 & 25.1 & 32.1 & 41.0 & 55.7 & 68.4 \\
\hline & Volume $\left(\mathrm{m}^{3}\right)$ & 397 & 144 & 173 & 294 & 385 & 502 & 487 \\
\hline & Yield Class $\left(\mathrm{m}^{2} \mathrm{ha}^{-1} \mathrm{yr}^{-1}\right)$ & 8.0 & 2.27 & 4.0 & 8.0 & 8.0 & 9.0 & 12.0 \\
\hline & Initial Spacing $(\mathrm{m})$ & 1.02 & 0.22 & 0.90 & 0.90 & 0.90 & 0.90 & 1.40 \\
\hline
\end{tabular}


first suggested by García (1979). This family of models uses a state-space approach to forecast the stand development based on a description of stands using four state variables: top height, number of stems per hectare, cylindrical stem volume (the product of basal area and top height), and occupancy. Occupancy is analogous to an interception efficiency: an index of the rate of gross photosynthesis versus a maximum potential rate, where a stand has enough leaves to intercept all photosynthetically available radiation (PAR - Monteith 1972).

Changes in the state variables through time are estimated by differential functions. The model variables are listed in Tab. 2. The SLeDG model was parametrised for Scots pine in three stages similar to García et al. (2011): height (site index, SI), mortality, and basal area with occupancy. Additionally, model outputs for merchantable volume were also parametrised. The biomass expansion factors (BEF) and root:shoot ratios of Levy et al. (2004) were used to provide standing biomass outputs based on the merchantable volume. Details of the model structure and parametrisation are available in Appendix 1.

Model statistics were calculated to provide an initial benchmark of the model fits to the data. As the dataset was small the statistics were only calculated with the PSP data used in model calibration, i.e., no independent data were used. Therefore a bootstrap analysis was used to provide a validation of the model as suggested by Vanclay \& Skovsgaard (1997).

One thousand bootstraps were run for each part of the model parametrisation resulting in confidence intervals for calibrated parameters. Variance inflation factors were calculated for each part of the model to assess multicollinearity between state variables Mean absolute difference, percent mean absolute difference, and the modelling efficiency were also calculated. Mean absolute difference is simply the average of all deviations of PSP data points from the model, which can also be expressed as a percentage. Modelling efficiency is described by Vanclay \& Skovsgaard (1997). It provides a statistic analogous to $\mathrm{R}^{2}$, whereby 1.00 represents "perfect" fit between model and measured data, and 0.00 represents a poor fit (negative values indicate very poor fit).

\section{PGN}

The 3PGN model is described in Xenakis et al. (2008) as a process based model structure coupling the 3PG model (Landsberg \& Waring 1997) with the introductory soil carbon model (ICBM - Andrén \& Kätterer 1997).

The 3PG model can be broadly separated into three parts. The first part deals with the derivation of the primary production: gross

Tab. 2 - Growth model variables and units.

\begin{tabular}{llll}
\hline Variable & Units & Definition & Kind \\
\hline$H$ & $\mathrm{~m}$ & Top height & State variables \\
$N$ & stems ha $^{-1}$ & Number of stems (per hectare) & \\
$W$ & $\mathrm{~m}^{3} \mathrm{ha}^{-1}$ & Stem wood; product of B and H & \\
$\Omega$ & - & Occupancy & Additional variables \\
\hline$H_{\mathrm{s}}$ & $\mathrm{m}$ & Site index & \\
$B$ & $\mathrm{~m}^{2} \mathrm{ha}^{-1}$ & Basal area & \\
$R$ & - & Relative closure & \\
$V$ & $\mathrm{~m}^{3} \mathrm{ha}^{-1}$ & Merchantable volume (stem to 7cm diam.) & \\
\hline
\end{tabular}

primary production is calculated using photosynthetically available radiation (PAR). PAR is estimated as half of incoming shortwave radiation (Landsberg \& Waring 1997). PAR is adjusted to available photosynthetically available radiation (APAR), scaled by a function of leaf area index. Dimensionless modifiers for vapour pressure deficit, soil water, temperature and age determine the utilisable APAR. Gross primary production is calculated by multiplying the utilisable APAR by an apparent canopy quantum efficiency which is usually assigned the value of

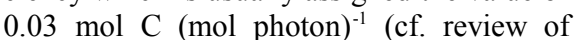
published literature by Landsberg \& Waring 1997). Finally gross primary production is simply scaled by $0.48 \pm 0.05$ to give Net Primary Production.

The second part determines the partitioning of the production to above and below ground portions (Landsberg et al. 2003). The production may be allocated to either the roots, stem, or foliage of a stand. Changes in biomass of roots, stem, and foliage is therefore the balance of the production allocated to each minus root dieback, stem mortality, and litterfall. The below ground portion of carbon allocation is determined by a fertility rating (a percentage site productivity rating), water content, and stand age. The above ground allocation of carbon is divided between stem and foliage using a ratio determined by basal area.

The third part produces outputs from the model such as stand volume, stem number, and basal area which may be of use to managers. Stem number change (mortality) is estimated by a version of the $-3 / 2$ self-thinning rule (Yoda 1963) which sets maximum number of stems $\left(N_{\max }\right)$ proportional to stem mass $\left(M_{\max }\right)$ according to $M_{\max }=k N_{\max }{ }^{-3 / 2}$, where $k$ is a coefficient to be estimated. Increases in stem mass are scaled to stand volume for output using an allometric relationship.

The Introductory Soil Carbon Model (ICBM - Andrén \& Kätterer 1997) is incorporated by including three carbon and three nitrogen pools for soil carbon. Each pool has different rates of decomposition, which may be further modulated by environmental conditions. Litterfall, root turnover and natural mortality calculated by $3 \mathrm{PG}$ are used as inputs to the soil carbon pools.
A previous calibration of $3 \mathrm{PGN}$ parameters for Scots pine (Xenakis et al. 2008) was used for this study. This used the same 51 plot dataset as the SLeDG parametrisation. The calibration was performed using an application of the Bayesian theorem with the implementation of a Monte Carlo Markov Chain. Calibration was performed for different plots and a mean parameter vector was extracted. For more details see Xenakis et al. (2008).

The model was run for each yield class. Average climatic and site conditions for each yield class (YC) were estimated based on mean climate for each yield class and a mean soil type estimated from 45 soil samples collected by Xenakis et al. (2012) from across Scotland. Solar radiation was estimated from temperature, humidity and site information using the algorithm given by Xenakis et al. (2008).

Thinning in 3 PGN is represented as a fraction of the biomass of foliage, wood and root of the mean tree removed in each intervention. To calculate the fractions for each yield class from the tables of Edwards \& Christie (1981), the biomass of the three structural pools before and after thinnings was calculated using the allometric equations developed by Xenakis et al. (2012). Thus the ratio of the biomass removed from thinnings to the biomass before thinnings was estimated. The model was run with and without thinnings.

\section{Forest Yield}

ForestYield (Forest Research 2001) is a computerised version of the yield tables of Edwards \& Christie (1981). It outputs top height, basal area, stem number, and volume for stands of given planting density, site quality (YC), and thinning regime. The equations used to calculate the yield tables are not utilised in ForestYield. Instead, it includes the data from the yield tables, and points in between table cells are mathematically interpolated. Stands that do not match these predetermined YCs, planting, and thinning regimes, are estimated by using the closest regime. To estimate stand whole tree biomass, ForestYield outputs were expanded with the biomass expansion factors estimates of Levy et al. (2004) as is performed in the land use, land use change and forestry (LU- 
Tab. 3 - Stand Level Dynamic Growth (SLeDG) model parameter estimates, errors, and confidence intervals calculated from bootstrap analysis for Scots pine. $(\dagger)$ : indicates fixed parameters (that were not adjusted in parametrisation).

\begin{tabular}{lllll}
\hline Parameter Value & $\begin{array}{l}\text { Standard } \\
\text { Error }\end{array}$ & $\begin{array}{l}\mathbf{9 5 \%} \\
\text { Confidence } \\
\text { Interval }\end{array}$ & Definition \\
\hline$b_{1}$ & $q$ & - & - & Height parameters \\
$b_{2}$ & 0.0200 & $1.31 \times 10^{-3}$ & $0.0121-0.0227$ & \\
$b_{3}$ & 0.859 & $2.98 \times 10^{-2}$ & $0.804-0.901$ & \\
\hline$q$ & - & - & - & Site quality measure \\
\hline$b_{4}$ & $7.57 \times 10^{-7}$ & $4.61 \times 10^{-7}-1.43-1.46$ & Mortality parameters \\
$b_{5}$ & 1.83 & 0.32 & $0.151-2.36$ & \\
$b_{6}$ & 1.86 & 0.17 & $1.13-2.34$ & \\
\hline$b_{7}$ & 0.249 & 0.464 & $0.142-0.274$ & Gross increment parameters \\
$b_{8}$ & 1.04 & 0.72 & $0.965-1.24$ & \\
$b_{9}$ & $0.4^{\dagger}$ & - & - & - \\
\hline$k$ & $b_{9}$ & - & - & Relative size mortality parameter \\
\hline$b_{10}$ & $2.4^{\dagger}$ & - & - & Occupancy exponent \\
\hline$b_{11}$ & 0.105 & 0.368 & $-2.79-0.943$ & Occupancy scalar \\
\hline$b_{12}$ & $2.778 \times 10^{4 \dagger}$ & - & - & Planting density for full closure at \\
& & & & planting \\
\hline$\beta_{\mathrm{v}}$ & 0.394 & $2.84 \times 10^{-3}$ & - & Merchantable volume scalar \\
\hline$c_{\mathrm{v}}$ & 11.0 & 1.94 & - & Merchantable volume intercept7 \\
\hline
\end{tabular}

LUCF) reporting in the UK (Dyson et al 2009), and in a similar manner to the SLeDG model.

\section{Model comparison and initiation}

Such different models are not easily compared statistically. Previous model comparisons have looked at errors when models have been validated against common data (Weiskittel et al. 2009a, Pinjuv et al. 2006) However, as all available Scots pine data were utilised in parametrisation of SLeDG and 3PGN, a similar comparison was not possible.

Instead, all three models were compared by looking at how each predicts a range of productivity classes (defined by YC) over one rotation of one hundred years. These represented hypothetical stands, rather than looking at specific stands which have been measured.

In order to compare the models predictions

of stands through time a standard of site quality is needed. ForestYield utilises yield class (YC) as its measure of site quality, however 3PGN and SLeDG require a conversion between their site quality measures and YC. In this study, even YCs ranging between 4 and $14 \mathrm{~m}^{3} \mathrm{ha}^{-1} \mathrm{yr}^{-1}$ were used. The $\mathrm{YC}$ is the estimated mean annual increment of a stand of trees which occurs at the intersection between the idealized curves for mean annual increment and current annual increment plotted against stand age (Edwards \& Christie 1981).

In the SLeDG model, SI is used as a measure of site quality. The relationship between $\mathrm{YC}$ and $\mathrm{SI}$ is given as (eqn. 1):

$$
Y C=\alpha_{1}+\alpha_{2} H s
$$

with a reference age of 50, $\alpha_{1}=-5.507$ and $\alpha_{2}=0.867\left(\mathrm{RMSE}=0.428, \mathrm{R}^{2}=0.981\right)$ for Scots pine (Fonweban 2012).

Fig. 1 - Model-data comparison of top height growth in Scots pine permanent sample plots. Modelled top height growth (dashed lines) for even site indices 10-22 (age 50) based on Scots pine PSP (permanent sample plot) data.

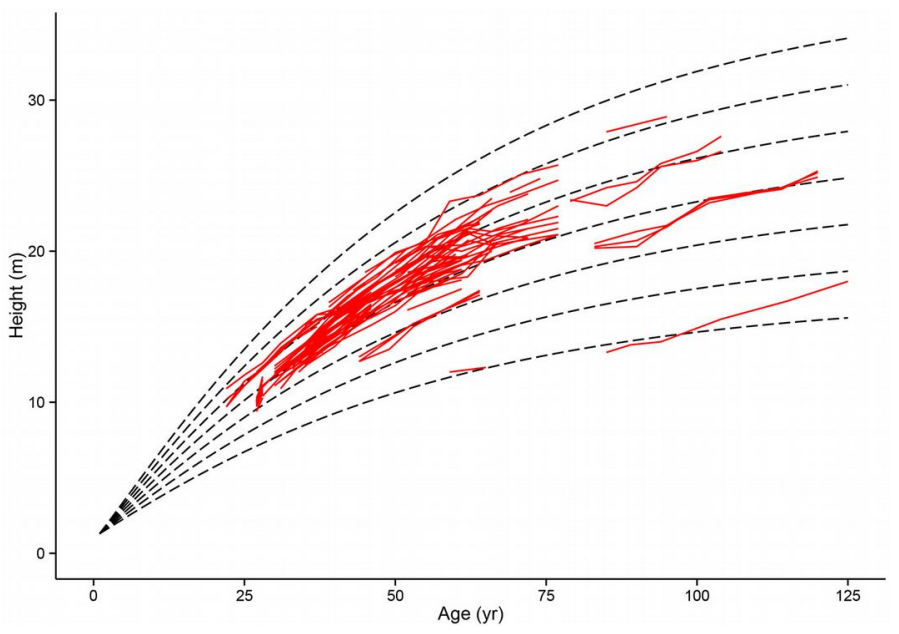

In 3 PGN site quality is represented by the fertility rating. The link between $3 \mathrm{PG}$ and ICBM which calculated the fertility rating parameter from ICBM's output was removed and so fertility rating was re-introduced as a parameter (Minunno et al. 2010).

The model was run using the parameter set of Xenakis et al. (2008 - fit to the same 51 PSPs) for each soil type. The fertility rating parameter was calibrated manually to achieve the closest fit of predicted against observed diameter at breast-height (dbh). The calibrated values of fertility rating were assigned to the different yield classes based on mean YC for a given soil type. For two YC $(8 \& 10)$ values for fertility rating were interpolated between the fitted fertility rating due to lack of stand data.

The predictions were initiated as follows: initial planting density was fixed at 2500 stems $\mathrm{ha}^{-1}$; a previous average for Scots pine planting in the UK (Forestry Commission, pers. comm.) and previously used in 3PGN forecasts by Xenakis (2007). It should be noted however that current grant applications for Scots pine forest establishment requires a density of $3000 \mathrm{stems} \mathrm{ha}^{-1}$ at establishment (Scottish Executive 2012). Assuming a constant initial planting density across modelling platforms provides a common starting point for forecasting hypothetical stand growth. Even YCs ranging between 4 and $14 \mathrm{~m}^{3} \mathrm{ha}^{-1} \mathrm{yr}^{-1}$ were forecast with each model.

Differences in outputs of top height, basal area, stem numbers, volume, and whole tree biomass were compared graphically over the range of productivity commonly seen in the UK. Similarities and differences in how the models forecast growth were considered and potential causes discussed. Additionally the requirements of the models in order that they may be run were compared, what parameters and variables are required in order to run a simulation of a stand, and how that relates to model purpose and utility.

\section{Results}

\section{SLeDG parametrisation}

The fitted parameters, their error, and bootstrap derived confidence intervals for the height-age and mortality sub-models are given in Tab. 3. The fit of these sub-models to the PSP data is shown in Fig. 1 and Fig. 2.

In the parametrisation for basal area and occupancy, the values for loblolly pine relating to occupancy and relative size of mortality loss $\left(b_{9}=0.4, b_{10}=2.4, b_{12}=2.778 \times\right.$ 104 - García et al. 2011) performed well due to the similarities in shade tolerance and thus self thinning between the pine species. Therefore, values for $b_{9}, b_{10}$ and $b_{12}$ were fixed in the parametrisations, as preliminary investigations showed no statistical improvement when these parameters were allowed to 
vary. These fixed values and the other estimated values for all parameters relating to basal area and occupancy are given in Tab. 3 . The errors are estimated from the Hessian calculated in the parametrisation, and confidence intervals are based on the bootstrap analysis.

The errors in the predicted value of basal area $(B)$ over the range of ages are given in Fig. 3. The linear model fitted to the errors has a slope significantly different to zero ( $\mathrm{P}$ $\left.=2.13 \times 10^{-4}\right)$, indicating consistent overestimation in the first 50 years and underestimation in years after.

The estimates of the coefficients from a linear regression of merchantable volume $(V)$ on the product of basal area and top height $(W)$ on aggregated data from the tree pulling database were $\beta_{\mathrm{v}}=0.394$ and $c_{\mathrm{v}}=11.01$. The regression had a $\mathrm{R}^{2}$ value of 0.978 .

The model for projecting forest stands can be summarised by the following equations (eqn. 2, 3, 4, and 5):

$$
\begin{aligned}
& \frac{d H}{d t}=0.0232\left[\left(\frac{q}{H}\right)^{0.859}-H\right] \\
& \frac{d N}{d H}=7.57 \cdot 10^{-7} H^{1.83} N^{1.86} \\
& \frac{d \Omega}{d H}=0.105 H^{1.04}(1-\Omega) \\
& \frac{d W}{d H}=0.249 \Omega H^{1.04} N^{0.4}-0.4 \frac{W}{N} \frac{d N}{d H}
\end{aligned}
$$

where $H, N, W$, and $\Omega$ are top height, number of stems per hectare, product of basal area and top height, and occupancy respectively. The local productivity is defined by the parameter $q$. The latter three equations may be multiplied by the first equation to express the variability in $N, \Omega$, and $W$ in terms of $d t$ instead of $d H$, and eqn. 3 may be substituted into eqn. 5 for a more standard form. All variance inflation factors in the model were less than 5 with the exception of top height in the stem wood accumulation function (eqn. 5) which was had a value of 7.40. This value is still below the threshold value of 10 suggested as a sign of high collinearity by Kutner et al. (2004). The statistics of model fit for SLeDG are given in Tab. 4 for $H$, $N$, and $B$. Overall there is high modelling efficiency for all three variables, indicating a good agreement between observed and estimated values. Although the lowest modelling efficiency is seen in $B$, it has a lower percentage mean absolute difference than $N$. Predictions of $H$ show the best agreement between observed and estimated values, with high modelling efficiency and the smallest percentage mean absolute difference.

\section{PGN Calibration}

All of the parameters but one used in this instance for 3PGN can be found in the cali-

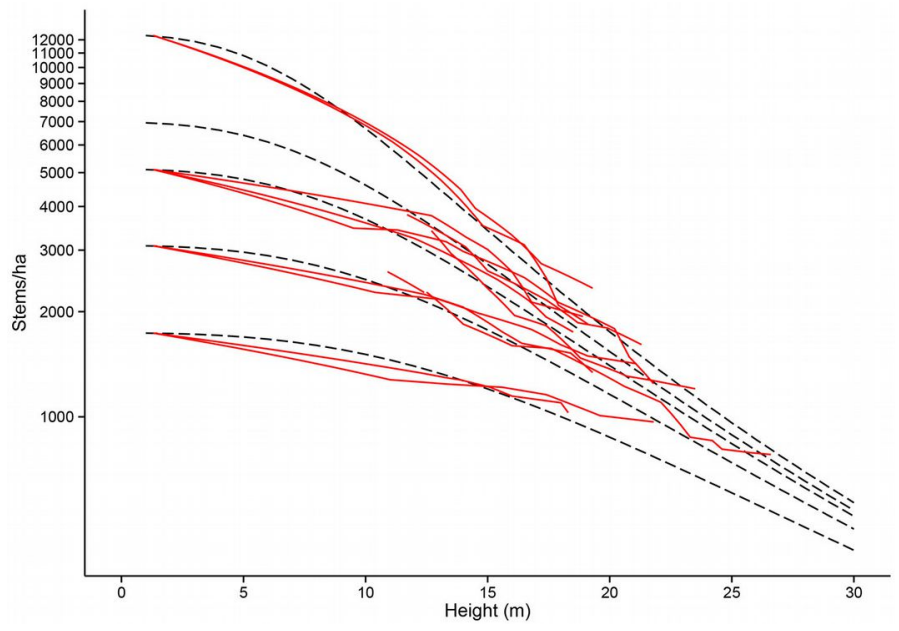

Fig. 2 - Model-data comparison of mortality in Scots pine permanent sample plots. Mortality of stands as top height increases for different initial planting densities. PSP (permanent sample plot) data is shown with the fitted model (dashed lines).

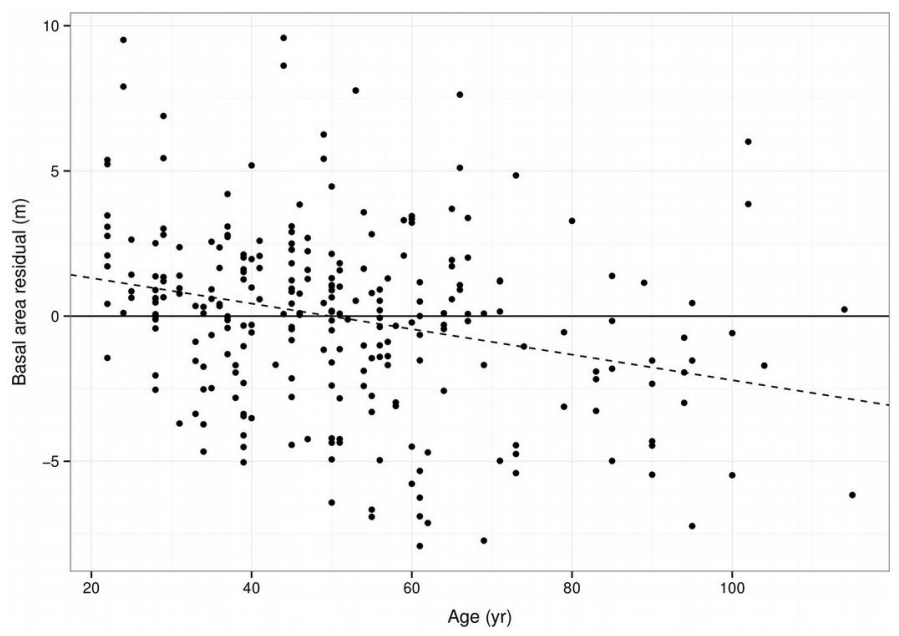

Fig. 3 - Error in basal area predictions using estimated parameters. Dashed line indicates a linear model fitted to the residuals.

bration for Scots pine by Xenakis et al. (2008) and Xenakis (2007). The only difference here is in the values of fertility rating. The range of fertility rating for given YC (and associated soil type) is given in Tab. 5. The proportion of explained variance by the regression of measured versus predicted $\mathrm{dbh}$

was always greater than 0.7 for all $\mathrm{YC}$ which had representative plots.

\section{Model predictions}

The variable output for unthinned and thinned stands for all three models can be seen in Fig. 4. The range of productivity between

Tab. 4 - Statistical measures of model fit in calibration against Permanent Sample Plot (PSP) data.

\begin{tabular}{lccc}
\hline Variable & $\begin{array}{c}\text { Top Height } \\
(\mathbf{m})\end{array}$ & $\begin{array}{c}\text { Stems } \\
\left(\mathbf{h a}^{-\mathbf{1}}\right)\end{array}$ & $\begin{array}{c}\text { Basal area } \\
\left(\mathbf{m}^{\mathbf{2}} \mathbf{h a}^{-\mathbf{1}} \mathbf{)}\right.\end{array}$ \\
\hline Mean absolute difference & 0.3521 & 130.1 & 2.551 \\
\% Mean absolute difference & 2.128 & 11.83 & 7.317 \\
Modelling efficiency & 0.9875 & 0.9334 & 0.9092 \\
\hline
\end{tabular}

Tab. 5 - Fertility rating values (percentage site productivity rating) for given soils and associated yield class (YC) based on regression between modelled and observed diameter at breast-height (dbh). (\$): interpolated values.

\begin{tabular}{lccc}
\hline Soil type & YC & $\begin{array}{c}\text { Fertility } \\
\text { rating }\end{array}$ & $\begin{array}{c}\text { Adjusted } \\
\mathbf{R}^{\mathbf{2}}\end{array}$ \\
\hline Podzol & 4 & 0.100 & 0.898 \\
Regosol & 6 & 0.265 & 0.747 \\
Gley & 8 & $0.300^{\ddagger}$ & - \\
Humicgley & 10 & $0.335^{\ddagger}$ & - \\
Podzol/Brownearth & 12 & 0.370 & 0.928 \\
Brownearth & 14 & 0.550 & 0.971 \\
\hline
\end{tabular}



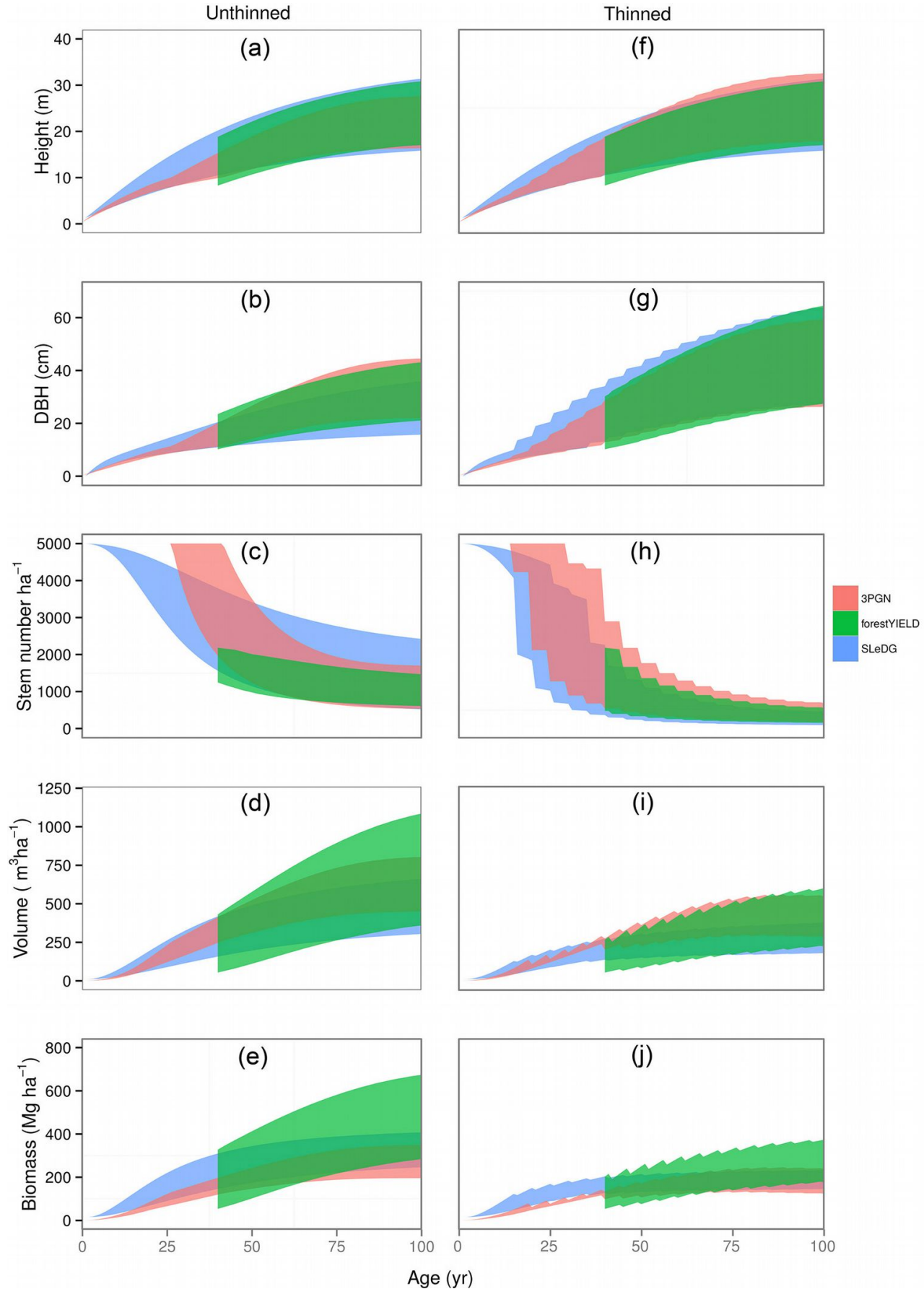

YC 4-14 is represented for each model by a different coloured ribbon. As ForestYield predictions only begin at age 40 for YC 4 stands, the ribbon representing ForestYield was truncated. Height and average dbh show similar trajectories over the range of productivities for all three models, in both thinned and unthinned stands.

There was no early mortality predicted by 3PGN until the age of 25 years or even later in less productive stands. As previously noted, ForestYield does not produce any mortality predictions before 40 years in $\mathrm{YC} 4$. ForestYield does produce mortality predic- tions for higher productivity stands younger than 40 years, though the earliest mortality is predicted at 25 years in YC 14 (Edwards \& Christie 1981). Only SLeDG was able to predict early stand mortality (Fig. 4c, Fig. 4h). In the unthinned stand simulation, 3PGN and ForestYield show reasonable agreement, with less than 1000 stems difference between most and least productive stands. The SLeDG model predicts a much wider difference in stem numbers between most and least productive YCs. When the thinned stands are simulated, there is better agreement between models (Fig. 4h).
Fig. 4 - Plots of SLeDG, 3PGN, and ForestYield thinned and unthinned stand predictions through time. Ribbons indicate range of productivity equivalent to YC 4 to 14 . DBH denotes diameter at breast-height. 
a much greater volume and biomass in higher yield class stands than both SLeDG and 3 PGN.

\section{Discussion and conclusions}

\section{SLeDG parametrisation}

The SLeDG model as summarised by eqn. 2-5 provides an alternative method for yield prediction in British stands of Scots pine Although parametrised with a small dataset, the model provides reasonable forecasts of Scots pine growth throughout the range of productivity observed in the UK.

Simultaneous parameter estimation has previously been identified as the best way to minimize model errors (Soares et al. 1995, Vanclay \& Skovsgaard 1997). The three stage fitting of SLeDG could therefore introduce additional error compared to a simultaneous fitting operation. However, it could equally be stated that the co-variation of model parameters can often make it difficult to identify the true optimum parameter configuration.

The site index model selected in the parametrisation produces an anamorphic set of curves (Fig. 1). While anamorphic height growth curves have been criticized in the past for their single point productivity classification (Zeide 1978), the selection versus alternative curve forms in the parametrisation indicates that this simple function is sufficient. Anamorphic curves have also been shown to be useful for UK Sitka spruce stands (Rennolls 1995).

The mortality section of the SLeDG model (Fig. 2) is an example of a self-thinning "law", as explained by García (2009). Thus, like other self-thinning laws such as the $-3 / 2$ law used in 3PGN, there is a maximum stem number for a stand of a given height or mass However, unlike the $-3 / 2$ law the SLeDG mortality parametrization provides a species specific mortality law. This is of benefit as previous studies have shown that the $-3 / 2 \mathrm{ex}$ ponent is inadequate in representing species specific shade tolerances (Weller 1987, Weiskittel et al. 2009b, Anfodillo et al. 2013). In this parametrization of SLeDG the trajectory of mortality for most stands is not dependent on this self-thinning line until greater heights are reached. This can be seen in Fig. 2 as the point when the models mortality projections come close together past stand heights of 20 $\mathrm{m}$.

Occupancy is an implicit (or latent) variable in this model as in previous parametrisations of SLeDG for other species (García et al. 2011). As such the values predicted by the model cannot be benchmarked against empirical data. Despite the fact that it is not a direct physical measure, occupancy is useful to provide a physiological limitation on stand productivity, similar to the PAR modulation by LAI in 3PGN, taking into account reductions in productivity at initial planting or following thinnings. In the future, it may be possible to estimate occupancy based on relative stand closure using Light Detection and Ranging (LiDAR) measurements. Alternatively, a method similar to that of Duursma et al. (2012) for estimating light use efficiency in woody plants may be scaled from individual plants to stand scale using LiDAR measurements to estimate occupancy directly.

Although the linear model fitted to the basal area residuals indicates a consistent bias which is a function of stand age, the linear model is likely to be affected by the few oldest plots ( $>70$ years) in the dataset. The older plot measurements in the PSP dataset tend to be less productive plots (Tab. 1), with more productive plots having been harvested. Thus the dataset is not representative of all productivity classes over the range of ages. As lower productivity stands are expected to have lower basal area in earlier stages of growth, this trend is likely to continue in later stages of the model, hence the potential for underestimation of basal area in older stands. Ideally PSP data from more productive, older stands would be included in a future parametrisation to remedy this.

The statistical tests to benchmark SLeDG (Tab. 4) reveal an excellent fit between the data and the model that has been fit to the data. A modelling efficiency so close to 1.0 is consistent with a graphical assessment of the model as can be seen in Fig. 1 and Fig. 2, where the model follows closely the measured values. Ideally independent data would have been used in a benchmark analysis. However, because of the small size of the PSP dataset, the decision was made to use all data in parametrisation. Bootstrap simulations are suggested as an alternative to independent validation in cases of data scarcity (Vanclay \& Skovsgaard 1997). Results of the bootstrap analysis were consistent with the parameter estimates when the whole dataset was used (Tab. 3). The parameter estimates for $b_{7}$ and $b_{8}$ do not sit in the middle of the bootstrap confidence intervals, which could be a result of bias in sampling of the bootstrap. Non-overlapping time intervals used in the parametrisation are assumed independent. However, plots with more measurements are more likely to be sampled repeatedly in the bootstrap which uses sampling with replacement.

Further improvements to SLeDG may include modulating the site index part of the model by a climate index (similar to the climate variables used in 3 PGN) to allow for predictions in a changing climate. Equally, a soil model may be integrated with the model as in 3PGN with a variable similar to fertility rating modulating the site index, and the occupancy providing values for fine root turnover and litter production. With this a mea- sure of soil carbon accumulation may be obtainable.

\section{Model comparison}

Despite their differences in structure, the three models show reasonable agreement in variables and outputs over the years predicted. This is especially true in the thinned stand projections. The main differences occurred in the predicted volume and biomass forecasts. The higher biomass estimates of SLeDG compared to 3PGN in unthinned stands (Fig. 4e) may be similar to overestimates of biomass seen when using BEF based on only one variable (Lehtonen et al. 2004), as the BEF is only based on top height (Levy et al. 2004).

Additionally, this discrepancy may be explained by the underestimation in biomass previously observed when using 3PGN to estimate Scots pine growth, due to an underestimated foliage biomass pool (Xenakis et al. 2008). As before, the cause of the underestimate of 3PGN may be better understood given a more complete dataset with foliage and root carbon storage in chronosequences. Regardless of the cause, both models forecast a smaller range of volumes and biomass than ForestYield. It is possible that the lower variation in stem numbers observed in ForestYield (Fig. 4c, Fig. 4h) does not represent the variation one might expect between very high and low productivity sites. If lower fertility sites had a higher stem number for a given height, the range in stand volume may be reduced to a range similar to that observed in the other two models.

In thinned stands, SLeDG and 3PGN arrive at a similar biomass estimate across the range of $\mathrm{YC}$, despite an earlier biomass accumulation predicted by SLeDG. However, SLeDG still predicts lower volumes in thinned stands. This may also be a symptom of the low number of older high productivity stands in the PSP dataset.

Alternative models for producing biomass outputs could be considered to estimate biomass both from SLeDG or ForestYield yield estimates instead of simple BEFs. EFISCEN (Nabuurs et al. 2002) and CBM-CFS3 (Kurz et al. 2009) are two models for estimating forest carbon driven by yield outputs that could potentially utilise the yield predictions of either SLeDG or ForestYield.

Despite the limited PSP data available for Scots pine in the UK the benefit of using the SLeDG approach is that it still provides a reasonable forecast of stand growth across a range of sites. There is a reduction in time and effort required to parametrise SLeDG versus 3PGN, which requires 50 parameters to be estimated (Xenakis et al. 2008) compared to the 13 in this parametrisation of SLeDG. Additionally, climatic variables including maximum and minimum monthly temperatures and precipitation may not be 
easily obtained, being dependent on the nearest weather station. However, improved data availability reduces this advantage of SLeDG over 3PGN. With increasing data availability from remote sensing sources, which may easily be utilised by 3 PGN in a similar way to 3PGS (Coops et al. 1998 Coops \& Waring 2001), the potential for using 3PGN in UK forests can only increase Indeed, the potential of 3PGN is that it may utilise a wider range of data for calibration should it become available: as well as fores growth variables, carbon fluxes measured by eddy covariance may be utilised by 3PGN for calibration and validation (Minunno et al. 2010).

In this model comparison, we provide no indication of the uncertainty in model predictions. Both SLeDG and 3PGN provide parameter error values, allowing for error in variables and output to be propagated to the state variables. ForestYield does not provide any uncertainty in its parameters, and the yield tables that it is based on also provide no error values (Edwards \& Christie 1981) In financial terms, a measure of uncertainty is highly desirable for estimating optimum harvest (Lohmander 1988). Equally for carbon storage, a measure of uncertainty is important for both policy makers and managers, with uncertainty in parameters identifying parts of models requiring further attention (Smith \& Heath 2001). Indeed, quantification of uncertainties features heavily in the guide for LULUCF reporting (IPCC 2003).

Bayesian approaches to forest model calibration such as those of Van Oijen et al (2013), Patenaude et al. (2008), and Xenakis et al. (2008) are one approach which could lead to better understanding of model uncertainty, and future work on models for stand level development should consider this as an option. More generally, greater transparency in the relationships, assumptions and limitations of empirical yield models used for timber estimation and as drivers for other models (e.g., carbon reporting - Milne et al. 1998), and wind risk estimation (Gardiner et al. 2004) can lead to wider utility and application.

While this paper has concentrated on Scots pine in particular, the calibration of both SLeDG and 3PGN to other species both in the UK and beyond is possible. Both models are aimed at forecasting even-age monocultures, limiting their use in more complex forest stand structures. As a counterpoint both models forecast stands based on the current state of the system without requiring historical measurements to estimate productivity, particularly useful in countries where details of forest establishment are not widely known. With hybrid models it is possible to allow for a greater range of forest management strategies than static tables. Forecasts can be based on the current state of a forest stand, rather than fitting a given stand to a predetermined growth trajectory. Thus, improved estimates of forest stand-level metrics in the UK should allow for flexibility in predictions following any alterations in forest management; the ability to utilise as much data as possible whilst being robust enough to be able to run efficiently with minimal data available; and also be fully documented in order that various sources of error may be accounted for. None of the models considered here reach such lofty goals. However, it seems of benefit to move towards dynamic models of forest growth for carbon stock estimation. With current data availability a dynamic model such as SLeDG can account for changes in forest management. Replacing the static yield table approach currently used in C-FLOW with growth predictions from a dynamic statistical model could provide growth estimates for forest management in cases where management has deviated from the traditional schemes included in the tables of Edwards \& Christie (1981). In addition it is then possible to run model based scenarios of alternative management approaches to inform management. In the future, when data from multiple sources (for example remote sensing, and sensor networks) become more available, models such as 3PGN may become more appropriate, providing both forecasts and insight into the underlying processes driving changes in forest growth. Indeed, it may be most appropriate to consider the use of both SLeDG and 3PGN in concert to provide forest growth forecasts in the future. Such an approach allows the ensemble of models to continue to benchmark check each other, whilst providing more information about the uncertainty of predictions.

\section{Acknowledgements}

We wish to thank the Forest Research Forest Mensuration, Modelling and Forecasting Group for the provision of ForestYield predictions and provision of PSP data. This work was funded by the UK National Environmental Research Council and Forestry Commission UK.

\section{References}

Almeida AC, Siggins A, Batista TR, Beadle C, Fonseca S, Loos R (2010). Mapping the effect of spatial and temporal variation in climate and soils on Eucalyptus plantation production with 3-PG, a process-based growth model. Forest Ecology and Management 259 (9): 1730-1740. doi: 10.1016/j.foreco.2009.10.008

Andrén O, Kätterer T (1997). ICBM: the introductory carbon balance model for exploration of soil carbon balances. Ecological Applications 7 (4): 1226-1236. - doi: 10.1890/1051-0761(1997) 007[1226:ITICBM]2.0.CO;2

Anfodillo T, Carrer M, Simini F, Popa I, Banavar
JR, Maritan A (2013). An allometry-based approach for understanding forest structure, predicting tree-size distribution and assessing the degree of disturbance. Proceedings of the Royal Society B: Biological Sciences 280: 1751. - doi: 10.1098/rspb.2012.2375

Blanco J, Seely B, Welham C, Scoullar K (2008). Complexity in modelling forest ecosystems: how much is enough? Forest Ecology and Management 256: 1646-1658. - doi: 10.1016/j.foreco. 2008.07.011

Broad LR, Lynch T (2006). Growth models for Sitka spruce in Ireland. Irish Forestry 63 (1-2): 53-79. [online] URL: http://www.societyofirishforesters.ie/pdf/Journals/2006_VOL63_NO1\&2. pdf\#page $=73$

Coops N, Waring R (2001). The use of multiscale remote sensing imagery to derive regional estimates of forest growth capacity using 3-PGS Remote Sensing of Environment 75 (3): 324334. - doi: 10.1016/S0034-4257(00)00176-0 Coops N, Waring R, Landsberg J (1998). Assessing forest productivity in Australia and New Zealand using a physiologically-based model driven with averaged monthly weather data and satellite-derived estimates of canopy photosynthetic capacity. Forest Ecology and Management 104: 113-127. - doi: 10.1016/S0378-1127(97)00248$\mathrm{X}$

Duursma R, Falster D, Valladares F, Sterck F, Pearcy R, Lusk C, Sendall K, Nordenstahl M, Houter N, Atwell B, Kelly N, Kelly J, Liberloo M, Tissue D, Medlyn B, Ellsworth D (2012). Light interception efficiency explained by two simple variables: a test using a diversity of small-to medium-sized woody plants. New Phytologist 193: 397-408. - doi: 10.1111/j.1469-81 37.2011.03943.x

Dyson K, Thomson A, Mobbs D, Milne R, Skiba U, Clark A, Levy P, Jones S, Billett M, Dinsmore K, Oijen M, Ostle N, Foereid B, Smith P, Matthews R, Mackie E, Bellamy P, Rivas-Casado M, Jordan C, Higgins A, Tomlinson R, Grace J, Parrish P, Williams M, Clement R, Moncrieff J, Manning A (2009). Inventory and projections of UK emissions by sources and removals by sinks due to land use, land use change and forestry. Annual report July 2009, Center for Ecology and Hydrology, Penicuik, UK, pp. 1-80. [online] URL: http://nora.nerc.ac.uk/9396/

Edwards PN, Christie J (1981). Yield models for forest management. HMSO, London, UK, pp. 132.

Fonweban J (2012). Modelled ForestYield yield tables. Forest Research Internal Report, Forest Research, Roslin, UK, pp. 1-14.

Forest Research (2001). ForestYield software. Forest Research, Alice Holt Forest, Binsted, East Hampshire District, UK.

Forestry Commission (2011). Standing timber volume for coniferous trees in Britain: National Forest Inventory Report. Forestry Commission, Edinburgh, UK, pp. 1-20.

García O (1979). Modelling stand development with stochastic differential equations. In: Proceedings of the FRI Symposium "Mensuration 
for Management Planning of Exotic Forest plantations" (Elliott D eds). New Zealand Forest Service 20: 315-333. [online] URL: http://web.unbc.ca/ garcia/publ/sym20.pdf

García O, Ruiz F (2003). A growth model for eucalypt in Galicia, Spain. Forest Ecology and Management 173: 49-62. - doi: 10.1016/S03781127(01)00817-9

García O (2009). A simple and effective forest stand mortality model. Mathematical and Computational Forestry and Natural-Resource Sciences (MCFNS) 1 (1): 1-9. [online] URL: http:// main.mcfns.com/index.php/Journal/article/view Article/4

García O (2011). A parsimonious dynamic stand model for interior spruce in British Columbia. Forest Science 57 (4): 265-280. [online] URL: http://www.ingentaconnect.com/content/saf/fs/2 011/00000057/00000004/art00001

García O, Burkhart HE, Amateis RL (2011). A biologically-consistent stand growth model for loblolly pine in the Piedmont physiographic region, USA. Forest Ecology and Management 262 (11): 2035-2041. - doi: 10.1016/j.foreco.2011. 08.047

García O (2013). Building a dynamic growth model for trembling aspen in western Canada without age data. Canadian Journal of Forest Research 43 (3): 256-265. - doi: 10.1139/cjfr-20120366

Gardiner B, Suárez J, Achim A, Hale S, Nicoll B (2004). Forest GALES - A PC-based wind risk model, user's guide. Forest Research, Roslin, UK, pp. 1-54.

IPCC (2003). Good practice guidance for land use, land-use change and forestry. United Nation Framework Convention on Climate Change, IGES for IPCC, Hayama, Japan, pp. 590.

Jandl R, Lindner M, Vesterdal L, Bauwens B, Baritz R, Hagedorn F, Johnson D, Minkkinen K, Byrne K (2007). How strongly can forest management influence soil carbon sequestration? Geoderma 137 (3-4): 253-268. - doi: 10.1016/j. geoderma.2006.09.003

Kurz WA, Dymond CC, White TM, Stinson G, Shaw CH, Rampley GJ, Apps MJ (2009). CBMCFS3: a model of carbon-dynamics in forestry and land-use change implementing IPCC standards. Ecological Modelling 220 (4): 480-504. doi: 10.1016/j.ecolmodel.2008.10.018

Kutner MH, Nachtsheim C, Neter J (2004). Applied linear regression models $\left(4^{\text {th }} \mathrm{edn}\right) . \mathrm{Mc}$ Graw-Hill/Irwin, New York, USA, pp. 701.

Landsberg J, Waring R (1997). A generalised model of forest productivity using simplified concepts of radiation-use efficiency, carbon balance and partitioning. Forest Ecology and Management 95 (3): 209-228. - doi: 10.1016/S0378-11 27(97)00026-

Landsberg J (2003). Physiology in forest models: history and the future. Forest Biometry, Modelling and Information Sciences 1: 49-63. [online] URL: http://cms1.gre.ac.uk/conferences/iufro/ FMA/ 3 1_LandsbergJ_1.pdf

Landsberg J, Waring R, Coops N (2003). Performance of the forest productivity model 3-PG ap- plied to a wide range of forest types. Forest Ecology and Management 172 (2-3): 199-214. - doi: 10.1016/S0378-1127(01)00804-0

Lehtonen A, Mäkipää R, Heikkinen J (2004). Biomass expansion factors (BEFs) for Scots pine, Norway spruce and birch according to stand age for boreal forests. Forest Ecology and Management 188 (1-3): 211-224. - doi: 10.1016/S03781127(03)00384-0

Levy PE, Hale SE, Nicoll BC (2004). Biomass expansion factors and root: shoot ratios for coniferous tree species in Great Britain. Forestry 77 (5): 421-430. - doi: 10.1093/forestry/77.5.421

Lohmander P (1988). Continuous extraction under risk. Systems Analysis Modelling Simulation 5: 339-354.

Mason EG, Methol R, Cochrane H (2011). Hybrid mensurational and physiological modelling of growth and yield of Pinus radiata D. Don. using potentially useable radiation sums. Forestry 84 (2): 99-108. - doi: 10.1093/forestry/cpq048 Milne R, Brown T, Murray T (1998). The effect of geographical variation of planting rate on the uptake of carbon by new forests of Great Britain. Forestry 71 (4): 297-310. - doi: 10.1093/forestry/ 71.4 .297

Minunno F, Xenakis G, Perks MP, Mencuccini M (2010). Calibration and validation of a simplified process-based model for the prediction of the carbon balance of Scottish Sitka spruce (Picea sitchensis) plantations. Canadian Journal of Forest Research 40 (12): 2411-2426. - doi: 10.1139/X10-181

Minunno F, Van Oijen M, Cameron D, Cerasoli S, Pereira J, Tomé M (2012). Analysing structural error and parameter uncertainty of two Eucalyptus models differing in representation of autotrophic respiration. In: "EGU General Assembly Conference Abstracts, vol. 14" (Abbasi A, Giesen N eds). Vienna (Austria), 22-27 April 2012. EGU General Assembly Conference Abstracts, pp. 1250. [online] URL: http://adsabs.harvard.edu/abs/2012eguga..14.1250m

Monserud RA (2003). Evaluating forest models in a sustainable forest management context. Forest Biometry, Modelling and Information 1: 35-47. [online] URL: http://cms1.gre.ac.uk/conferences/ iufro/fbmis/A/3_1_MonserudR_1.pdf

Monteith JL (1972). Solar radiation and productivity in tropical ecosystems. The Journal of Applied Ecology 9 (3): 747. - doi: 10.2307/24019 01

Nabuurs GJ, Pussinen A, Karjalainen T, Erhard M, Kramer K (2002). Stemwood volume increment changes in European forests due to climate change - a simulation study with the EFISCEN model. Global Change Biology 8 (4): 304-316. doi: 10.1046/j.1354-1013.2001.00470.x

Nijnik M, Mather A (2007). Analysing institutions and public perspectives to identify the future of British forests. In: "Sustainable Forestry From Monitoring and Modelling to Knowledge Management and Policy Science" (Reynolds KM, Thomson AJ, Köhl M, Shannon MA, Ray Rennolls DK eds). CAB International, Wallingford, UK, pp. 171-188. [online] URL: http://
books.google.com/books?id=1-U50NX-IHIC Patenaude G, Milne R, Van Oijen M, Rowland CS, Hill RA (2008). Integrating remote sensing datasets into ecological modelling: a Bayesian approach. International Journal of Remote Sensing 29 (5): 1295-1315. - doi: 10.1080/0143116 0701736414

Pinjuv G, Mason EG, Watt M (2006). Quantitative validation and comparison of a range of forest growth model types. Forest Ecology and Management 236 (1): 37-46. - doi: 10.1016/j.foreco.2006.06.025

Pretzsch H (2010). Forest dynamics, growth, and yield. Springer, Berlin, Heidelberg, Germany, pp. 664. - doi: 10.1007/978-3-540-88307-4

Pyatt G, Ray D, Fletcher J (2001). An ecological site classification for forestry in Great Britain. Bulletin 124, Forestry Commission, Edinburgh, UK, pp. 75.

Pérez-Cruzado C, Muñoz Sáez F (2011). Combining empirical models and the process-based model 3-PG to predict Eucalyptus nitens plantations growth in Spain. Forest Ecology and Management 262: 1067-1077. - doi: 10.1016/j.foreco. 2011.05.045

Rennolls K (1995). Forest height growth modelling. Forest Ecology and Management 71 (3): 217-225. - doi: 10.1016/0378-1127(94)06102-O Sands P, Landsberg J (2001). Parameterisation of 3-PG for plantation grown Eucalyptus globulus. Forest Ecology and Management 163 (1-3): 273292. - doi: 10.1016/S0378-1127(01)00586-2

Scottish Executive (2012). Woodland creation productive conifer (high cost) woodlands (RP22 301B). Web site. [online] URL: http://www.scotland.gov.uk/Topics/farmingrural/SRDP/RuralPri orities/Options/WoodlandCreation/ConiferHighCost

Smith J, Heath L (2001). Identifying influences on model uncertainty: an application using a forest carbon budget model. Environmental Management 27 (2): 253-267. - doi: 10.1007/s0026700 10147

Soares P, Tome M, Skovsgaard J, Vanclay J (1995). Evaluating a growth model for forest management using continuous forest inventory data. Forest Ecology and Management 71 (3): 251-265. - doi: 10.1016/0378-1127(94)06105-R Swenson J, Waring R, Fan W, Coops N (2005). Predicting site index with a physiologically based growth model across Oregon, USA. Canadian Journal of Forest Research 35 (7): 16971707. - doi: 10.1139/x05-089

Valentine HT, Mäkelä A (2005). Bridging process-based and empirical approaches to modeling tree growth. Tree Physiology 25 (7): 769-79. - doi: 10.1093/treephys/25.7.769

Van Oijen M, Reyer C, Bohn F, Cameron D, Deckmyn G, Flechsig M, Härkönen S, Hartig F, Huth A, Kiviste A, Lasch P, Mäkelä A, Mette T, Minunno F, Rammer W (2013). Bayesian calibration, comparison and averaging of six forest models, using data from Scots pine stands across Europe. Forest Ecology and Management 289: 255-268. - doi: 10.1016/j.foreco.2012.09.043

Vanclay J, Skovsgaard J (1997). Evaluating forest 
growth models. Ecological Modelling 98 (1): 112. - doi: 10.1016/S0304-3800(96)01932-1

Vanclay JK (1994). Modelling forest growth and yield. CAB International, Oxon, UK, pp. 330. [online] URL: http://epubs.scu.edu.au/cgi/viewcontent. cgi? article $=1538 \&$ context $=$ esm_pubs Weiskittel A, Maguire D, Monserud R (2009a). Development of a hybrid model for intensively managed Douglas-fir in the Pacific Northwest. In: "Forest Growth and Timber Quality: Crown Models and Simulation Methods for Sustainable Forest Management" (Dykstra, DP, Monserud RA). General Technical Report PNW-GTR-791, Pacific Northwest Research Station, USDA Forest Service, Portland, OR, USA, pp. 49-67. [online] URL: http://www.cabdirect.org/abstrac ts/20093236555.html

Weiskittel A, Gould P, Temesgen H (2009b) Sources of variation in the self-thinning boundary line for three species with varying levels of shade tolerance. Forest Science 55 (1): 84-93. [online] URL: http://www.ingentaconnect.com/ content/saf/fs/2009/00000055/00000001/art0000 8

Weller DE (1987). Self-thinning exponent correlated with allometric measures of plant geometry. Ecology 68 (4): 813-821. - doi: 10.2307/1938 352

Woodland Expansion Advisory Group (2012). Report of the woodland expansion advisory group. The Scottish Government, Edinburgh, UK, pp. 92.

Xenakis G (2007). Assessment of carbon sequestration and timber production of Scots pine across Scotland using the process-based model 3-PGN. PhD thesis, University of Edinburgh, Edinburgh, UK, pp. 289.

Xenakis G, Ray D, Mencuccini M (2008). Sensitivity and uncertainty analysis from a coupled 3PG and soil organic matter decomposition model. Ecological Modelling 219 (1-2): 1-16. - doi: 10.1016/j.ecolmodel.2008.07.020
Xenakis G, Ray D, Mencuccini M (2012). Effects of climate and site characteristics on Scots pine growth. European Journal of Forest Research 131: 427-439. - doi: 10.1007/s10342-011-05162

Yoda K (1963). Self-thinning in over-crowded pure stands under cultivated and natural conditions. XI. Intraspecific competition among higher plants. Journal of Biology Osaka City University $14: 107-129$.

Zeide B (1978). Standardization of growth curves. Journal of Forestry 76 (5): 289-292. [online] URL: http://www.ingentaconnect.com/content/ saf/jof/1978/00000076/00000005/art00014

\section{Supplementary Material}

Appendix 1 - Details of the parametrisation of the SLeDG model.

Link: Lonsdale_1403@supp1001.pdf 